\title{
Is the Screening Test of the French Version of the Dementia Quality of Life Questionnaire Indispensable?
}

\author{
A. Wolak ${ }^{a, b}$ J.-L. Novella ${ }^{a, c} \quad$ M. Drame ${ }^{a, c} \quad$ I. Morrone ${ }^{a, c}$ \\ F. Boyer ${ }^{a, d}$ F. Blanchard ${ }^{a, c}$ D. Jolly ${ }^{a, b}$
}

${ }^{a}$ Faculty of Medicine, University of Reims Champagne-Ardenne, EA 3797,

${ }^{b}$ Clinical Research Coordination Unit, Robert Debré Hospital, University Hospital of Reims, 'Department of Clinical Gerontology, Maison Blanche Hospital, University Hospital of Reims, dPhysical Medicine and Rehabilitation, Sébastopol Hospital, University Hospital of Reims, Reims, France

\section{Key Words}

Dementia $\cdot$ DQoL, French version $\cdot$ Psychometric validation $\cdot$ Quality of life $\cdot$ Screening test

\begin{abstract}
The aim of this study was to evaluate the usefulness of the screening questions in the French version of the Dementia Quality of Life (DQoL) questionnaire. To assess the psychometric properties of the French DQoL, 155 patients with mild-to-moderate dementia were recruited. Here, we compared the psychometric properties of the instrument between patients who passed the screening test $(n=109)$ and the whole study population $(n=155)$. The French DQoL version showed a good test-retest reliability at a 2-week interval $(0.95 \leq$ intraclass correlation coefficients $\leq 1.0)$, and an average internal consistency ( $0.58 \leq$ Cronbach's $\alpha \leq 0.87)$ for the 2 study groups. Significant differences were observed in the 2 groups for 4 dimensions of the DQoL regarding dementia severity (Cornell scale), and for 3 dimensions evaluating depression (MMSE). Convergent validity with the Duke Health Profile revealed many significant correlations between dimensions not only in the 109 patients, but also in the whole study population. Our study demonstrated that patients who failed the screening procedure nonetheless seemed to be able to answer the DQoL questionnaire, the whole study group showing acceptable psychometric properties.

Copyright ๑ 2011 S. Karger AG, Basel
\end{abstract}




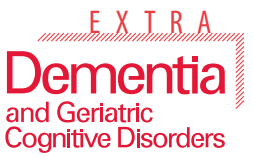

\begin{tabular}{l|l}
\hline Dement Geriatr Cogn Disord Extra 2011;1:84-92 \\
\hline DOl: 10.1159/000326782 & $\begin{array}{l}\text { ○ } 2011 \text { S. Karger AG, Basel } \\
\text { www.karger.com/dee }\end{array}$ \\
\hline Published online: April 6, 2011 &
\end{tabular}

Wolak et al.: Use of the Screening Test in the French DQoL

\section{Introduction}

In the setting of dementia, it is important to understand the patients' perception of their own health. Specific tools to evaluate health-related quality of life (QoL) in dementia have been developed. Previously, it was assumed that dementia patients cannot be assessed; however, evaluation of the psychometric qualities of available tools has proved that evaluation of health-related QoL is also possible in demented subjects.

The Dementia QoL (DQoL) questionnaire is a specific tool to assess QoL in the context of mild-to-moderate dementia. It is one of the most frequently used assessment tools among those currently available. A special characteristic of the DQoL is that it starts with 3 screening questions to be answered before proceeding with the main questionnaire. These screening questions aim to verify whether or not the respondent is capable of understanding the instrument. If a patient has more than 1 incorrect answer, administration of the main questionnaire is considered impossible. The percentage of patients who failed the screening test was reported to be $4.0 \%$ in the initial validation [1]. Our study aimed to describe the psychometric properties of the transcultural adaptation of the DQoL into French [2], using data from all patients, including those who failed and those who passed the screening test, respectively.

\section{Methods}

Description of the DQoL

The DQoL was developed by Brod et al. [1] in 1999. It was first validated in a sample of 99 patients with mild-to-moderate dementia [Mini Mental State Examination (MMSE) $\geq 10$ ]. The questionnaire is administered by an interviewer and takes approximately $10 \mathrm{~min}$. The DQoL is composed of 29 items forming 5 groups: self-esteem (4 items), positive affect and humor (6 items), negative affect (11 items), feeling of belonging ( 3 items), and sense of esthetics (5 items). Each item is scored on a 5 -point scale.

\section{Psychometric Validation of the French Version}

Study Design

A multicenter cross-sectional study repeated at a 2-week interval between March 2006 and November 2007 was performed in 6 French hospitals and 1 French-speaking Swiss hospital. The Institutional Review Board of the University Hospital in Reims (France) approved the study. Informed consent was obtained from all patients and their caregivers after providing specific information on the study. Patients were free to refuse or opt out at any time without any impact on subsequent care. The study was conducted in compliance with good clinical and epidemiologic practice and the Declaration of Helsinki [3].

\section{Study Population}

Patients were recruited from centers with a memory clinic or a geriatric ward. Inclusion criteria were age $\geq 65$ years; dementia as defined by the DSM IV criteria and validated by a senior geriatrician; mild-to-moderate dementia as defined by an MMSE score $\geq 10$; being native French speakers; availability of a main caregiver able to complete the questionnaire, and living at home or in an institution. We defined 3 groups: firstly, patients who failed the screening test (i.e. $>1$ incorrect answer out of the 3 screening questions); secondly, patients who passed the screening test, and thirdly, the entire study population comprising both patients who passed and patients who failed the screening test. 
Data Collection

Data were entered into specific case report forms by trained interviewers. Sociodemographic variables recorded during the study were age, gender, marital status, place of residence, and level of education. The caregiver burden as determined by the caregiver burden scale of Zarit et al. [4] was also recorded.

Cognitive deficit was assessed by Folstein's [5] version of the MMSE and by clinical evaluation of dementia severity using Hughes's [6] Clinical Dementia Rating scale (CDR). Two scales were used to evaluate functional autonomy: Katz's [7] Activities of Daily Living (ADL) and Lawton's [8] Instrumental Activities of Daily Living (IADL). Behavior was assessed by the Neuropsychiatric Inventory (NPI) [9] and Cornell Depression scale [10].

Comorbidities were measured with the Charlson index [11] adapted to the ICD-10 version by Sundararajan et al. [12], and QoL was evaluated with the specific instrument under study (DQoL) and with a generic instrument, namely the Duke Health Profile [13].

\section{Statistical Analysis}

Feasibility and acceptability of the questionnaire were assessed by the rate of refusals to participate or withdrawals, and the rate of non-response. Ceiling and floor effects were calculated. Discriminant validity of the DQoL was assessed in terms of severity of cognitive decline (in 2 subgroups, i.e. subjects with MMSE $<18$ vs. $\geq 18$ ), and in terms of depression (in 2 subgroups, i.e. Cornell index $<8$ vs. $\geq 8$ ). For these comparisons, Student's $t$ tests were used.

Convergent validity was assessed by calculating correlations between the DQoL dimensions and the Duke Health Profile, IADL, NPI, Cornell index, CDR, and MMSE using Spearman's correlation coefficient.

Test-retest reliability at a 2-week interval was assessed using the intraclass correlation coefficient (ICC). An ICC $>0.8$ indicates good test-retest reliability [14]. Internal consistency of the DQoL was tested using Cronbach's $\alpha$ coefficient. The threshold for acceptable reliability was set at $\alpha \geq 0.7$ [14].

For all statistical tests, a p value $<0.05$ was considered statistically significant. Analyses were performed using SAS software (version 9.0; SAS Institute Inc., Cary, N.C., USA).

\section{Results}

\section{Patient Characteristics}

The total population included 155 patients, of whom 46 (29.7\%) answered more than 1 of the prerequisite screening questions incorrectly (table 1). The remaining 109 patients passed the screening test and were included in the analysis of the psychometric properties of the French version of the DQoL.

\section{Instrument Acceptability, Floor and Ceiling Effect}

There were no refusals to participate and no withdrawals from the study. No floor or ceiling effect was observed (table 2).

\section{Discriminant Validity}

In the group of 46 patients who failed the screening test, discriminant validity was low due to lack of power (table 3). However, when the group of 109 patients who passed the screening test and completed the questionnaire was compared to the overall population of 155 , a good level of discriminant validity was observed in each group. We obtained 4 significant differences between dimension scores for the MMSE subgroups (threshold $\geq 18$ ): 


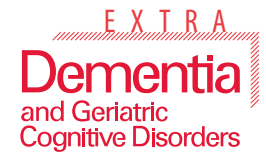

Table 1. Patient characteristics

\begin{tabular}{|c|c|c|c|c|c|c|c|}
\hline & \multicolumn{2}{|c|}{$\begin{array}{l}\text { Whole population } \\
(\mathrm{n}=155)\end{array}$} & \multicolumn{2}{|c|}{$\begin{array}{l}\text { Patients who passed the } \\
\text { screening procedure } \\
(\mathrm{n}=109)^{1}\end{array}$} & \multicolumn{2}{|c|}{$\begin{array}{l}\text { Patients who failed the } \\
\text { screening procedure } \\
(\mathrm{n}=46)\end{array}$} & \multirow{2}{*}{$\begin{array}{l}\text { Comparison } \\
\text { between the } 2 \\
\text { subgroups } \\
\mathrm{p}\end{array}$} \\
\hline & $\mathrm{n}$ & $\%$ & $\mathrm{n}$ & $\%$ & $\mathrm{n}$ & $\%$ & \\
\hline Female gender & 98 & 63.2 & 68 & 62.4 & 30 & 65.2 & 0.86 \\
\hline Type of dementia & & & & & & & 0.52 \\
\hline Alzheimer's disease & 122 & 78.7 & 84 & 77.1 & 38 & 82.6 & \\
\hline Other dementia & 33 & 21.3 & 25 & 22.9 & 8 & 17.4 & \\
\hline Cornell scale & & & & & & & 0.19 \\
\hline$<8$ & 121 & 79.1 & 82 & 75.9 & 39 & 86.7 & \\
\hline$\geq 8$ & 32 & 20.1 & 26 & 24.1 & 6 & 13.3 & \\
\hline Zarit scale & & & & & & & 0.84 \\
\hline$<21$ & 50 & 40.7 & 36 & 40.0 & 14 & 42.4 & \\
\hline$\geq 21$ & 73 & 59.3 & 54 & 60.0 & 19 & 57.6 & \\
\hline CDR & & & & & & & 0.01 \\
\hline 0.5 & 41 & 26.6 & 36 & 33.3 & 5 & 10.9 & \\
\hline 1 & 68 & 44.2 & 45 & 41.7 & 23 & 50.0 & \\
\hline 2 & 41 & 26.6 & 26 & 24.1 & 15 & 32.6 & \\
\hline \multirow[t]{2}{*}{3} & 4 & 2.6 & 1 & 0.9 & 3 & 6.5 & \\
\hline & $\mathrm{n}$ & mean $\pm \mathrm{SD}$ & $\mathrm{n}$ & mean $\pm S D$ & $\mathrm{n}$ & mean $\pm \mathrm{SD}$ & $\mathrm{p}$ \\
\hline Age, years & 155 & $81.8 \pm 6.0$ & 109 & $81.1 \pm 6.1$ & 46 & $83.3 \pm 5.4$ & 0.04 \\
\hline MMSE & 155 & $20.8 \pm 4.4$ & 109 & $21.2 \pm 4.3$ & 46 & $19.9 \pm 4.4$ & 0.09 \\
\hline $\mathrm{ADL}$ & 153 & $4.9 \pm 1.4$ & 108 & $5.1 \pm 1.3$ & 45 & $4.5 \pm 1.4$ & 0.01 \\
\hline $\mathrm{IADL}^{2}$ & 152 & $3.5 \pm 2.3$ & 107 & $3.9 \pm 2.4$ & 45 & $2.4 \pm 1.6$ & $<0.001$ \\
\hline NPI, global score & 146 & $13.7 \pm 11.6$ & 104 & $14.0 \pm 11.2$ & 42 & $12.9 \pm 12.6$ & 0.59 \\
\hline Charlson index & 155 & $2.1 \pm 1.2$ & 109 & $2.1 \pm 1.3$ & 46 & $2.0 \pm 1.0$ & 0.52 \\
\hline
\end{tabular}

${ }^{1}$ More than 1 exact answer in the first form. ${ }^{2}$ IADL by PAQUID (4 items).

self-esteem, positive affect/humor, feeling of belonging, and sense of esthetics. We also observed 3 significant differences between dimension scores for the Cornell scale subgroups (threshold $\geq 8$ ): self-esteem, positive affect/humor, and negative affect.

\section{Convergent Validity}

For the related measures (IADL, NPI, Cornell index, CDR, and MMSE), analysis of the whole study population $(\mathrm{n}=155)$ revealed 3 additional significant correlations when compared to the subgroup of 109 patients who passed the screening test (MMSE self-esteem: $\mathrm{p}<$ 0.05; MMSE sense of esthetics: $\mathrm{p}<0.05$; CDR positive affect/humor: $\mathrm{p} \leq 0.01$ ), whereas 1 correlation that was significant in the subgroup of 109 patients (CDR feeling of belonging: $\mathrm{p}<0.05$ ) was no longer significant in the analysis of all 155 patients (table 4).

When we compared the Duke Health Profile and the DQoL (table 5), we noticed that all the dimensions of the Duke Health Profile were significantly linked with at least 1 DQoL dimension for the groups of 109 and 155 patients, with similar levels of correlation.

\section{Reliability}

In the group of 109 patients, ICCs were between 0.95 and 1.00, showing good reliability (table 6). For the 46 patients who failed the screening test and the overall population of 155 patients, ICC had almost the same values (0.96-1.00). 


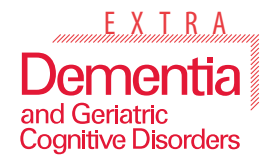

\begin{tabular}{l|l}
\hline \multicolumn{2}{l}{ Dement Geriatr Cogn Disord Extra 2011;1:84-92 } \\
\hline DOI: 10.1159/000326782 & $\begin{array}{l}\text { @ 2011 S. Karger AG, Basel } \\
\text { www.karger.com/dee }\end{array}$ \\
Published online: April 6, 2011 & \multicolumn{2}{l}{}
\end{tabular}

Table 2. Instrument acceptability, floor and ceiling effects

\begin{tabular}{|c|c|c|c|c|c|c|c|c|c|c|c|c|c|}
\hline \multirow[t]{2}{*}{ Dimension } & \multirow[t]{2}{*}{$\begin{array}{l}\text { Items } \\
\mathrm{n}\end{array}$} & \multicolumn{4}{|c|}{ Whole population $(\mathrm{n}=155)$} & \multicolumn{4}{|c|}{$\begin{array}{l}\text { Patients who passed the } \\
\text { screening procedure }(n=109)\end{array}$} & \multicolumn{4}{|c|}{$\begin{array}{l}\text { Patients who failed the } \\
\text { screening procedure }(n=46)\end{array}$} \\
\hline & & $\mathrm{n}$ & $\begin{array}{l}\text { mean } \\
\pm S D\end{array}$ & $\begin{array}{l}\text { floor } \\
\text { effect, \% }\end{array}$ & $\begin{array}{l}\text { ceiling } \\
\text { effect, \% }\end{array}$ & $\mathrm{n}$ & $\begin{array}{l}\text { mean } \\
\pm S D\end{array}$ & $\begin{array}{l}\text { floor } \\
\text { effect, \% }\end{array}$ & $\begin{array}{l}\text { ceiling } \\
\text { effect, \% }\end{array}$ & $\mathrm{n}$ & $\begin{array}{l}\text { mean } \\
\pm S D\end{array}$ & $\begin{array}{l}\text { floor } \\
\text { effect, \% }\end{array}$ & $\begin{array}{l}\text { ceiling } \\
\text { effect, } \%\end{array}$ \\
\hline \multirow{2}{*}{\multicolumn{14}{|c|}{ Positive affect/ }} \\
\hline & & & & & & & & & & & & & \\
\hline humor & 6 & 152 & $3.5 \pm 0.8$ & 0.7 & 1.3 & 109 & $3.6 \pm 0.8$ & 0.9 & 1.8 & 43 & $3.3 \pm 0.8$ & 2.3 & 4.6 \\
\hline Negative affect & 11 & 152 & $2.4 \pm 0.8$ & 2.6 & 0.7 & 109 & $2.4 \pm 0.8$ & 2.7 & 0.9 & 43 & $2.3 \pm 0.7$ & 2.3 & 2.3 \\
\hline \multicolumn{14}{|l|}{ Feeling of } \\
\hline belonging & 3 & 149 & $3.5 \pm 0.9$ & 1.3 & 4.0 & 108 & $3.6 \pm 0.9$ & 0.9 & 5.6 & 41 & $3.4 \pm 0.9$ & 2.4 & 4.9 \\
\hline Sense of esthetics & 5 & 147 & $3.3 \pm 0.8$ & 0.7 & 1.4 & 106 & $3.3 \pm 0.8$ & 0.9 & 0.9 & 41 & $3.0 \pm 0.8$ & 2.4 & 2.4 \\
\hline
\end{tabular}

Table 3. Discriminant validity (Student's t test)

\begin{tabular}{|c|c|c|c|c|c|c|}
\hline & \multicolumn{3}{|c|}{ MMSE (mean \pm SD) } & \multicolumn{3}{|c|}{ Cornell scale (mean \pm SD) } \\
\hline & $<18$ & $\geq 18$ & $\mathrm{p}$ & $<8$ & $\geq 8$ & $\mathrm{p}$ \\
\hline \multicolumn{7}{|c|}{ Whole population $(n=155)$} \\
\hline Total & 31 & 124 & & 121 & 32 & \\
\hline Self-esteem & $3.0 \pm 0.8$ & $3.4 \pm 0.8$ & $\leq 0.01$ & $3.4 \pm 0.8$ & $2.9 \pm 0.8$ & $\leq 0.001$ \\
\hline Positive affect/humor & $3.0 \pm 1.0$ & $3.7 \pm 0.7$ & $\leq 0.001$ & $3.6 \pm 0.8$ & $3.1 \pm 0.9$ & $\leq 0.01$ \\
\hline Negative affect & $2.3 \pm 0.9$ & $2.4 \pm 0.7$ & & $2.2 \pm 0.7$ & $3.0 \pm 0.8$ & $\leq 0.001$ \\
\hline Feeling of belonging & $3.0 \pm 1.0$ & $3.6 \pm 0.8$ & $\leq 0.001$ & $3.6 \pm 0.8$ & $3.3 \pm 1.0$ & \\
\hline Sense of esthetics & $2.9 \pm 0.8$ & $3.4 \pm 0.8$ & $\leq 0.01$ & $3.3 \pm 0.8$ & $3.1 \pm 0.9$ & \\
\hline \multicolumn{7}{|c|}{ Patients who passed the screening procedure $(n=109)$} \\
\hline Total & 20 & 89 & & 82 & 26 & \\
\hline Self-esteem & $3.0 \pm 1.0$ & $3.5 \pm 0.7$ & $\leq 0.01$ & $3.6 \pm 0.7$ & $2.9 \pm 0.8$ & $\leq 0.001$ \\
\hline Positive affect/humor & $3.0 \pm 1.1$ & $3.7 \pm 0.7$ & $\leq 0.01$ & $3.7 \pm 0.7$ & $3.2 \pm 1.0$ & $\leq 0.01$ \\
\hline Negative affect & $2.5 \pm 1.0$ & $2.5 \pm 0.7$ & & $2.3 \pm 0.7$ & $3.1 \pm 0.8$ & $\leq 0.001$ \\
\hline Feeling of belonging & $3.0 \pm 0.9$ & $3.7 \pm 0.8$ & $\leq 0.001$ & $3.6 \pm 0.8$ & $3.3 \pm 0.9$ & \\
\hline Sense of esthetics & $2.9 \pm 0.9$ & $3.4 \pm 0.8$ & $<0.05$ & $3.3 \pm 0.8$ & $3.2 \pm 0.9$ & \\
\hline \multicolumn{7}{|c|}{ Patients who failed the screening procedure $(n=46)$} \\
\hline Total & 11 & 35 & & 39 & 6 & \\
\hline Self-esteem & $3.1 \pm 0.5$ & $3.2 \pm 0.8$ & & $3.2 \pm 0.7$ & $2.9 \pm 0.4$ & \\
\hline Positive affect/humor & $3.1 \pm 0.8$ & $3.4 \pm 0.8$ & & $3.4 \pm 0.8$ & $2.9 \pm 0.7$ & \\
\hline Negative affect & $2.1 \pm 0.6$ & $2.3 \pm 0.7$ & & $2.2 \pm 0.7$ & $2.7 \pm 0.6$ & \\
\hline Feeling of belonging & $3.2 \pm 1.1$ & $3.5 \pm 0.8$ & & $3.4 \pm 0.8$ & $3.0 \pm 1.2$ & \\
\hline Sense of esthetics & $2.9 \pm 0.7$ & $3.3 \pm 0.9$ & & $3.3 \pm 0.8$ & $2.5 \pm 0.5$ & \\
\hline
\end{tabular}

The group of 109 patients showed good internal consistency (Cronbach's $\alpha$ between 0.70 and 0.87 ). For all 155 patients, Cronbach's $\alpha$ varied from 0.69 to 0.87 . Two dimensions (selfesteem and feeling of belonging) were $<0.70$, indicating moderate internal consistency. For the group of 46 patients, Cronbach's $\alpha$ varied from 0.58 to 0.87 , with a value $<0.70$ in only 1 dimension, namely self-esteem. 


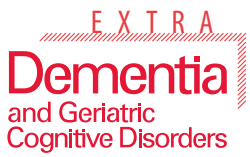

\begin{tabular}{l|l}
\hline Dement Geriatr Cogn Disord Extra 2011;1:84-92 \\
\hline $\begin{array}{l}\text { DOI: 10.1159/000326782 } \\
\text { Published online: April 6, } 2011\end{array}$ & $\begin{array}{l}\text { @ 2011 S. Karger AG, Basel } \\
\text { www.karger.com/dee }\end{array}$ \\
\hline
\end{tabular}

Wolak et al.: Use of the Screening Test in the French DQoL

Table 4. Convergent validity (Spearman's correlations with related measures)

\begin{tabular}{|c|c|c|c|c|c|}
\hline & Self-esteem & $\begin{array}{l}\text { Positive } \\
\text { affect/humor }\end{array}$ & $\begin{array}{l}\text { Negative } \\
\text { affect }\end{array}$ & $\begin{array}{l}\text { Feeling } \\
\text { of belonging }\end{array}$ & $\begin{array}{l}\text { Sense } \\
\text { of esthetics }\end{array}$ \\
\hline \multicolumn{6}{|c|}{ Whole population $(n=155)$} \\
\hline $\mathrm{IADL}^{1}$ & $0.19^{*}$ & 0.07 & $0.25^{* *}$ & 0.09 & 0.07 \\
\hline NPI & -0.11 & -0.10 & $0.23^{* *}$ & 0.10 & -0.01 \\
\hline Cornell & $-0.27^{* * *}$ & $-0.26^{* * *}$ & $0.36^{* * *}$ & -0.12 & $-0.18^{*}$ \\
\hline CDR & $-0.26^{* *}$ & $-0.22^{* *}$ & -0.02 & -0.13 & $-0.17^{*}$ \\
\hline MMSE & $0.18^{*}$ & $0.21^{* *}$ & 0.02 & 0.15 & $0.17^{*}$ \\
\hline \multicolumn{6}{|c|}{ Patients who passed the screening procedure $(n=109)$} \\
\hline IADL & $0.21^{*}$ & -0.01 & $0.21^{*}$ & 0.14 & 0.06 \\
\hline NPI & -0.18 & -0.16 & $0.27^{* *}$ & 0.00 & -0.04 \\
\hline Cornell & $-0.34^{* * *}$ & $-0.31^{* * *}$ & $0.40^{* * *}$ & -0.18 & $-0.26^{* *}$ \\
\hline CDR & $-0.27^{* *}$ & -0.18 & 0.05 & $-0.20^{*}$ & $-0.22 *$ \\
\hline MMSE & 0.19 & $0.21^{*}$ & 0.04 & 0.18 & 0.16 \\
\hline \multicolumn{6}{|c|}{ Patients who failed the screening procedure $(n=46)$} \\
\hline IADL & 0.02 & 0.19 & $0.32 *$ & -0.15 & 0.11 \\
\hline NPI & -0.02 & -0.03 & 0.08 & 0.31 & 0.02 \\
\hline Cornell & -0.22 & -0.24 & 0.23 & -0.05 & 0.02 \\
\hline CDR & -0.09 & -0.18 & -0.10 & 0.17 & 0.01 \\
\hline MMSE & 0.11 & 0.15 & -0.07 & 0.04 & 0.16 \\
\hline
\end{tabular}

\section{Discussion}

Our study showed that subjects with mild-to-moderate dementia who passed or failed the screening procedure nonetheless seemed to be able to answer the DQoL questionnaire, which proved to be able to reveal interesting psychometric properties.

To evaluate the objective status of patients with dementia, physicians usually use specific tools such as CDR, MMSE or ADAS-cog for cognitive status, NPI or Cornell scale for behavior, and ADL or IADL for autonomy. It is virtually always possible to perform an evaluation using these tools. However, these objective evaluations do not provide information on the patients' own perception of their disease. This complementary field of subjective evaluation, such as self-reported QoL evaluation, is increasingly considered to be as important as objective evaluation.

Among the tools available to measure specific QoL in the context of dementia, the DQoL presents several advantages; it can, for example, be used in any type of dementia, it is completed by the patient, and it has different scores, a global score and a score for each dimension. Furthermore, it contains one original dimension, i.e. sense of esthetics. However, it also possesses a screening procedure, and in theory, if patients fail the screening test, they are excluded. This principle of exclusion might be too restrictive in the light of our results. Indeed, some patients may truly be unable to answer any questions, so it is logical to exclude them. However, it is equally important that the tool does not exclude too many patients. Geriatricians and neurologists need available tools, such as the DQoL, in order to take selfreported QoL into account in their daily practice when evaluating subjects with dementia and measuring effects of prescribed care or of re-education. In our study, $29.7 \%$ of the pa- 


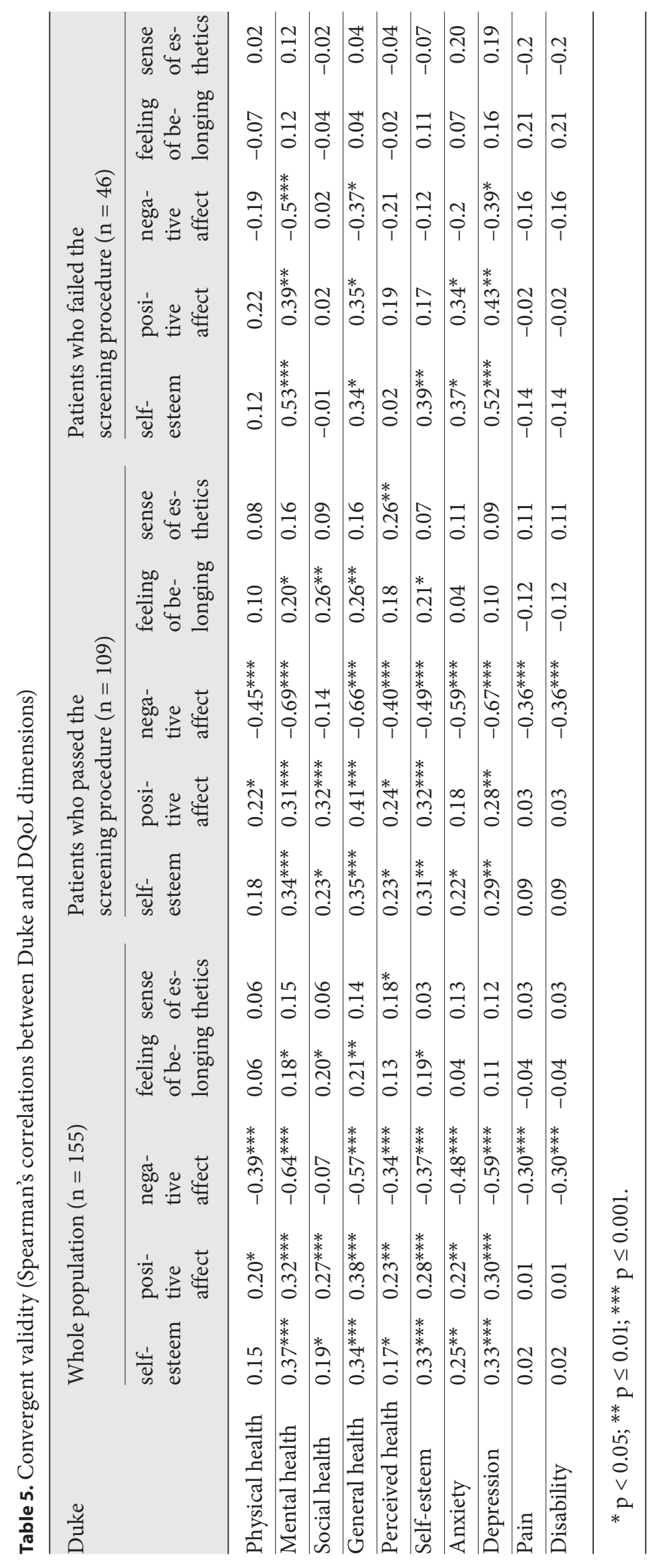


Table 6. Reliability

\begin{tabular}{|c|c|c|c|c|c|c|}
\hline \multirow[t]{2}{*}{ Dimension } & \multicolumn{3}{|c|}{ Test-retest reliability ${ }^{1}$} & \multicolumn{3}{|c|}{ Internal consistency ${ }^{2}$} \\
\hline & $\mathrm{n}=155$ & $\mathrm{n}=109$ & $\mathrm{n}=46$ & $\mathrm{n}=155$ & $\mathrm{n}=109$ & $\mathrm{n}=46$ \\
\hline Self-esteem & 0.98 & 0.97 & 0.99 & 0.69 & 0.72 & 0.58 \\
\hline Positive affect/humor & 0.99 & 0.99 & 0.98 & 0.84 & 0.85 & 0.79 \\
\hline Negative affect & 1.00 & 1.00 & 1.00 & 0.87 & 0.87 & 0.87 \\
\hline Feeling of belonging & 0.96 & 0.95 & 0.96 & 0.69 & 0.70 & 0.70 \\
\hline Sense of esthetics & 0.97 & 0.96 & 0.99 & 0.74 & 0.75 & 0.72 \\
\hline
\end{tabular}

tients included had actually failed the screening test. If the exclusion criterion had been applied as recommended, the reliability of the questionnaire would have been considerably diminished. Other specific tools like the QoL-AD [15] or the DEMQOL [16] do not present this type of limitation. Previous studies recommended to select patients with an MMSE score $\geq 10$. Our results showed that the psychometric properties (test-retest, internal consistency, and convergent and discriminant validity) were not much different whether patients who failed the screening test were included into the analysis or not. Nevertheless, these psychometric properties could not be accurately investigated because of the small sample size of the subgroup of 46 patients (lack of power). Accordingly, we suggest that the 3 screening questions could be used as a training step. Thus, all patients with mild-to-moderate dementia could be evaluated with the DQoL, although results of patients who did not pass the screening test should be interpreted with caution.

\section{References}

1 Brod M, Stewart AL, Sands L, Walton P: Conceptualization and measurement of quality of life in dementia: the dementia quality of life instrument (DQoL). Gerontologist 1999;39:25-35.

2 Schwebel G, Dramé M, Jolly D, Boyer F, Morrone I, Di Pollina L, Aquino JP, Pfitzenmeyer P, Rouaud O, George MY, Ankri J, Blanchard F, Novella JL: Validation psychométrique du questionnaire Dementia Quality of Life (DQoL) en langue française. Revue Gériatr 2010;35:93-100.

3 World Medical Association Declaration of Helsinki - Ethical Principles for Medical Research Involving Human Subjects (http://www.wma.net/en/30publications/10policies/b3/index.html).

-4 Zarit SH, Todd PA, Zarit JM: Subjective burden of husbands and wives as caregivers: a longitudinal study. Gerontologist 1986;26:260-266.

-5 Folstein M, Folstein SE, McHugh PR: 'Mini-mental state'. A practical method for grading the cognitive state of patients for the clinician. J Psychiatr Res 1975;12:189-198.

-6 Hughes CP, Berg L, Danziger WL, Coben LA, Martin RL: A new clinical scale for the staging of dementia. Br J Psychiatry 1982;140:566-572.

7 Katz S, Akpom CA: A measure of primary socio-biological functions. Int J Health Serv 1976;6:493508.

$\rightarrow 8$ Lawton M, Brody E: Assessment of older people: self-maintaining and instrumental activities of daily living. Gerontologist 1969;9:179-186.

19 Cummings J, Mega M, Gray K, Rosenberg-Thompson S, Carusi DA, Gombein J: The Neuropsychiatric Inventory: comprehensive assessment of psychopathology in dementia. Neurology 1994;44: 2308-2314.

-10 Alexopoulos GS, Abrams RC, Young RC, Shamoian CA: Cornell Scale for Depression in Dementia. Biol Psychiatry 1988;23:271-284. 
-11 Charlson ME, Pompei P, Ales KL, MacKenzie CR: A new method of classifying prognostic comorbidity in longitudinal studies: development and validation. J Chronic Dis 1987;40:373-383.

-12 Sundararajan V, Henderson T, Perry C, Muggivan A, Quan H, Ghali W: New ICD-10 version of the Charlson comorbidity index predicted in-hospital mortality. J Clin Epidemiol 2004;57:1288-1294.

$\checkmark 13$ Parkerson GJ, Broadhead WE, Tse CK: The Duke Health profile. A 17-item measure of health and dysfunction. Med Care 1990;28:1056-1072.

14 Nunnally J: Psychometric Theory. New York, McGraw-Hill, 1978.

-15 Logsdon RG, Gibbons LE, McCurry SM, Teri L: Assessing quality of life in older adults with cognitive impairment. Psychosom Med 2002;64:510-519.

-16 Smith SC, Lamping DL, Banerjee S, Harwood RH, Foley B, Smith P, et al: Development of a new measure of health-related quality of life for people with dementia: DEMQOL. Psychol Med 2007;37: 737-746. 